\title{
Effect of the Simultaneous Variation in Blade Root Chord Length and Blade Taper on Helicopter Flight Control Effort
}

\author{
Tugrul Oktay ${ }^{1}$ and Firat Sal ${ }^{2}$ \\ ${ }^{1}$ Aeronautical Engineering Department, Erciyes University, Kayseri, Turkey \\ ${ }^{2}$ Kelkit College of Aydin Dogan, Gumushane University, Gumushane, Turkey \\ Correspondence should be addressed to Tugrul Oktay; tugruloktay52@gmail.com
}

Received 18 August 2017; Revised 30 October 2017; Accepted 19 November 2017; Published 21 December 2017

Academic Editor: Linda L. Vahala

Copyright (C) 2017 Tugrul Oktay and Firat Sal. This is an open access article distributed under the Creative Commons Attribution License, which permits unrestricted use, distribution, and reproduction in any medium, provided the original work is properly cited.

\begin{abstract}
In this study, the effect of simultaneous variation in blade root chord length and blade taper on the control effort of helicopter flight control system (i.e., FCS) of a helicopter is investigated. Therefore, helicopter models (i.e., complex, control-oriented, and physicsbased models) including the main physics and essential dynamics are used. The effect of simultaneous variation in the blade root chord length and blade taper (i.e., in both chordwise and lengthwise directions dependently) on the control effort of an FCS of a helicopter and also on the closed-loop responses is studied. Comparisons in terms of the control effort and peak values with and without variations in the blade root chord and blade taper changes are carried out. For helicopter FCS variance-constrained controllers, specific output variance-constrained controllers are beneficial.
\end{abstract}

\section{Introduction}

Previously, technologies for minimizing the control effort of a flight control system (FCS) of a helicopter were regularly and universally examined. Some of these methods include moving the tail using collective and differential pitch angle variations of the left and right side of the horizontal tail and the forward and backward motion of the tail in longitudinal axis (e.g., see $[1,2])$. Other methods include redesigning some of the helicopter main rotor parameters (e.g., radius, chord length, and flapping spring stiffness) before flight (i.e., passive morphing) and continuously changing some of the helicopter main rotor parameters (e.g., radius and chord length) during flight (i.e., active morphing). For example, in [3], passive morphing was beneficial for decreasing the control effort. In that study, the main rotor blade radius, blade chord length, blade twist, blade linear mass density, blade flapping spring stiffness, and angular speed were the passive morphing parameters. The use of this novel technology helped save $33 \%$ of the control effort of the FCS for a straight-and-level flight at 40 knots. In addition to the previous study, in [4], active morphing was beneficial for the same reason. In that study, the main rotor blade radius, blade chord length, blade twist, and angular speed were the active morphing parameters. The use of this novel technology helped save $84.6 \%$ of the control effort of the FCS for a straight-and-level flight at 40 knots.

Several studies on the helicopter blade root chord length and blade taper have been conducted recently for different reasons. For example, in [5], flapwise bending vibration analysis of a rotating, tapered cantilever Bernoulli-Euler beam (e.g., helicopter blade) was conducted using the differential transform method (i.e., DTM). The effect of blade taper on natural frequencies was also studied. It was found that the natural frequencies of a rotating, tapered cantilever Bernoulli-Euler beam can be obtained with high accuracy by using the DTM. In another study by Ozdemir and Kaya [6], the free vibration analysis of a rotating, double-tapered Timoshenko beam (e.g., helicopter blade) in which flapwise bending and torsional vibrations are coupled was studied. Moreover, in [7], the taper ratio was studied in order to optimize the hover performance. The design concerns related to tapering were the taper ratio, point of taper beginning, and blade root chord. In that study, some additional parameters, 




FIGURE 1: Effect of blade taper on control effort for 40-knot straight-and-level flight condition (taken from [10]).

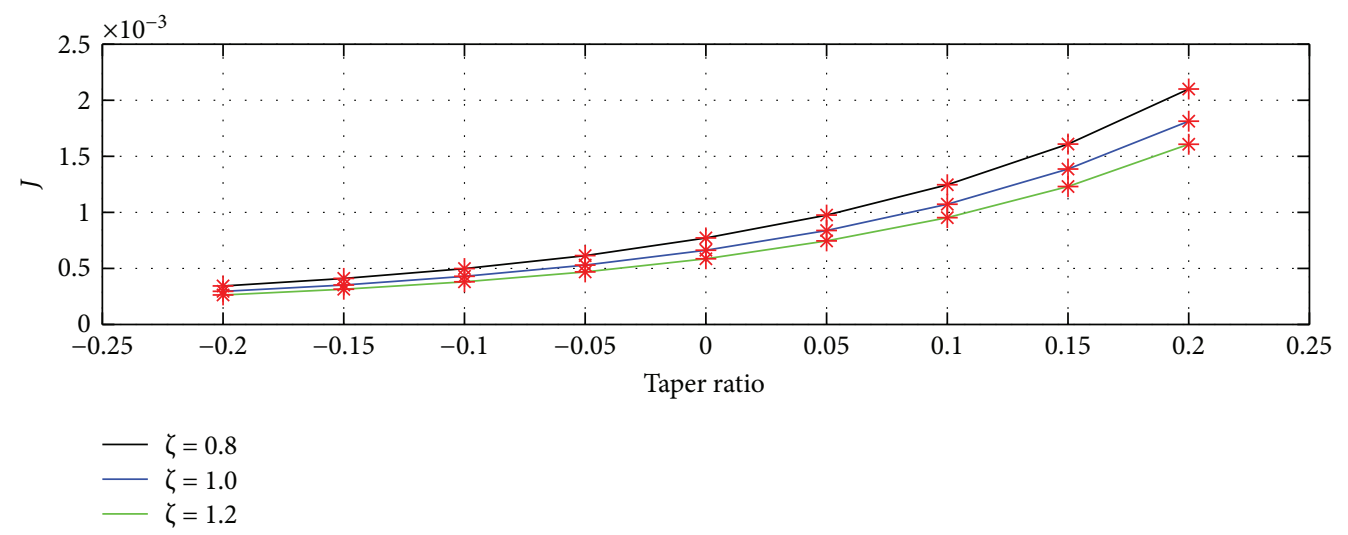

FIGURE 2: Effect of both blade root chord length and blade taper on control effort for 40-knot straight-and-level flight condition (taken from [11]).

that is, the blade twist and coefficients of the airfoil distribution function, were also investigated. After optimization, the required horsepower reduced by $7.4 \%$ and the figure of merit for hover improved by $6.5 \%$ (see also $[8,9]$ for different blade taper applications). In addition to the previously mentioned studies, the effect of blade taper on the control effort of the flight control system of a helicopter was also studied by Oktay and Sal [10]. In that study, the blade taper and the gains of the output variance-constrained controller(OVC-) based helicopter FCS were the optimization variables. These variables were optimized in order to decrease the control effort. After applying a positive blade taper, the control effort was increased. Therefore, using a positive blade taper was found impractical for their system. Figure 1 shows some of the results found in that study. Since it was found that just applying blade taper is impractical from the perspective of reducing the control effort of the FCS of a helicopter, in another conference study of Oktay and Sal [11], the helicopter blade taper and blade root chord length were designed simultaneously with the gains of the OVC-based helicopter FCS in order to optimize the control effort. Figure 2 shows some of the results found in that study ( $\zeta$ refers to the coefficient with which the root chord length is multiplied).

Several control methods for the helicopter FCS have been developed recently. The use of variance-constrained controllers is one such method (see [12]). These types of controllers have numerous advantages with respect to the other existing well-known controllers in the literature. First, varianceconstrained controllers are enhanced LQG controllers and they include the Kalman filters for state estimators. Second, they provide second-order information (i.e., state covariance matrix, see $[13,14]$ for more information), and this type of information is very beneficial during multivariable control system design since all stabilizing controllers are parameterized in relation to the physically meaningful state covariance matrix. Last, for large and strongly coupled multi-input, multioutput systems, for example, the ones used in helicopter FCSs, these controllers distribute guarantees on the transient behavior of independent variables through enforcing upper limits on the variance of these variables. In this study, a specific variance-constrained controller, the OVC, is applied to a helicopter FCS owing to these several advantages.

In this study, the combined effect of the helicopter blade taper and blade root chord length on the control effort of the FCS of a helicopter is for the first time evaluated with OVCs. Moreover, comparisons in terms of the peak values of closed-loop responses with and without variations in the blade root chord and blade taper changes are carried out and also evaluated for the first time in the literature. The preliminary results were presented at an international conference (i.e., International Research Conference on Science, Management and Engineering [11]).

\section{Helicopter Model and Helicopter Blade}

In this study, the helicopter models produced in [12] and summarized in $[3,4]$ are used. These are briefly summarized next. They include the physics principles, which lead 




(a)

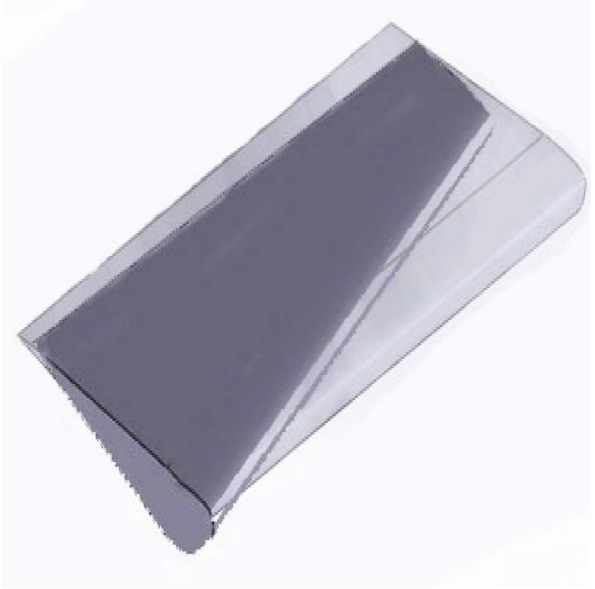

(b)

Figure 3: Tapered helicopter blade. (a) Tapered blade. (b) Both tapered and untapered blades.

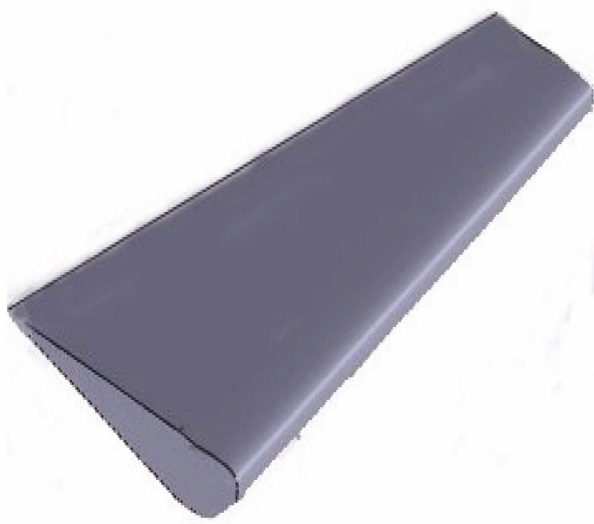

(a) Original blade

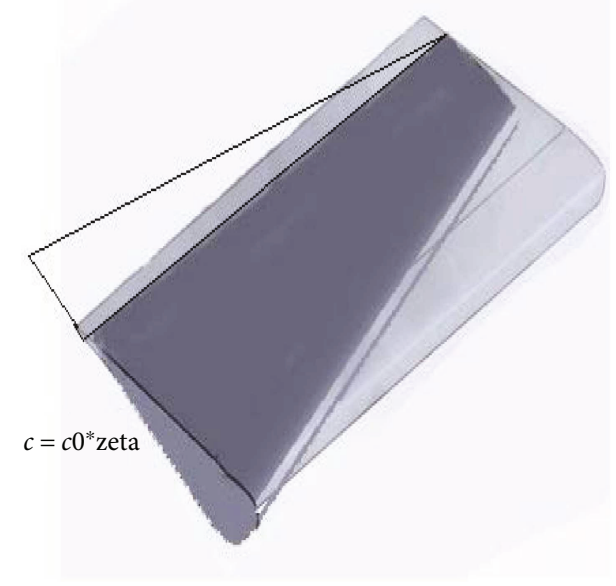

(b) Blade with variation

FIGURE 4: Illustration of variation in blade root chord.

to dynamic models consisting of a finite set of ordinary differential equations (ODEs). The helicopter model found using the philosophy summarized previously includes the fuselage, empennage, landing gear, fully articulated main rotor (i.e., with four blades), main-rotor downwash, and tail rotor. Consequently, the model is objectively complex with a total of 29 equations: 9 fuselage equations, 16 blade flapping and lead-lagging equations, 3 static main-rotor downwash equations, and an additional flight-path angle algebraic equation.

In this study, the effect of simultaneous variation in blade root chord length and blade taper on helicopter FCS is investigated. Therefore, the reason for studying the blade taper is summarized next: blade taper is employed for improving the aerodynamic efficiency $[15,16]$ and preventing over structural bending stresses at the blade root [17]. Constant chord blades are simple to produce, but they are aerodynamically less efficient than tapered blades. The blade taper also improves the helicopter rotor hover performance and forward flight performance until around the advance ratio of 0.3. Owing to these several advantages, in this study, the blade taper is considered and its effect on the control effort of the FCS of a helicopter simultaneously with the blade root chord is examined. Figure 3 shows a tapered blade. Moreover, in Figure 4, the variation in the blade root chord length with blade taper is shown.

In Figure 5, the variation in both blade taper and blade root chord is shown.

\section{Helicopter Flight Control System}

For a helicopter FCS, a variance-constrained controller, specifically the OVC is chosen. Brief description and applications of OVCs can be found in [13, 14] (see also [18] for background of OVC).

For a given continuous linear time-invariant (LTI), stabilizable, and detectable plant (see $[13,14]$ )

$$
\begin{aligned}
\dot{x}_{p} & =A_{p} x_{p}+B_{p} u_{p}+w_{p}, \\
y & =C_{p} x_{p}, \\
z & =M_{p} x_{p}+v,
\end{aligned}
$$




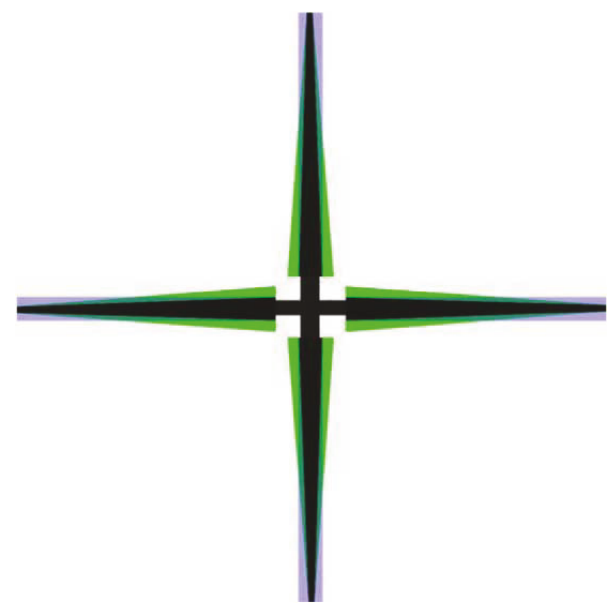

FIGURE 5: Illustration of variation in both blade taper and blade root chord (i.e., purple: original blade; black: tapered blade; green: both tapered and root chord-varied blade).

and a positive definite input penalty matrix, $\mathbf{R}>0$, determines a full-order dynamic controller

$$
\begin{aligned}
& \dot{x}_{c}=A_{c} \mathbf{x}_{\mathrm{c}}+\mathbf{F} z, \\
& u_{p}=\mathbf{G} \mathbf{x}_{c},
\end{aligned}
$$

in response to the problem

$$
\min _{A_{c}, \mathbf{F}, \mathbf{G}} \quad J=E_{\infty} u_{p}^{\mathbf{T}} \mathbf{R} u_{p}=\operatorname{tr}\left(\mathbf{R} \mathbf{G} \mathbf{X}_{c_{j}} \mathbf{G}^{\mathbf{T}}\right),
$$

exposed to variance constraints on the outputs

$$
E_{\infty} y_{i}^{2} \leq \sigma_{i}^{2}, \quad i=1, \ldots, n_{y} .
$$

In the above equation, $y$ and $z$ characterize the outputs of interest and sensor measurements, respectively; F and G are the state estimator and controller gain matrices, respectively; $w_{p}$ and $v$ are zero-mean uncorrelated Gaussian white noises with intensities of $W$ and $V$, respectively; $\mathbf{x}_{\mathrm{c}}$ is the controller state vector; $\sigma_{i}^{2}$ is the upper limit imposed on the $i$ th output variance; $n_{y}$ is the number of outputs; and $E_{\infty} \triangleq \lim _{t \rightarrow \infty} E$, where $E$ is the expectation operator. In addition to previous information, $\mathbf{t r}$ and $\mathbf{T}$ symbolize the matrix trace and matrix transpose operators, respectively. The quantity of $J$ is generally termed as the control effort of the FCS or the cost of the FCS, and it is obtained using the state covariance matrix, $\mathbf{X}_{\mathrm{c}_{j}}$. After the algorithm $[13,14]$ converges and the output penalty matrix $\mathbf{Q}$ is found, the OVC parameters are

$$
\begin{aligned}
A_{c} & =A_{p}+B_{p} \mathbf{G}-\mathbf{F} M_{p}, \\
\mathbf{F} & =X M_{p}^{\mathrm{T}} V^{-1}, \\
\mathbf{G} & =-\mathbf{R}^{-1} B_{p}^{\mathrm{T}} K .
\end{aligned}
$$

In the above equation, $X$ and $K$ are solutions of two algebraic Riccati equations:

$$
\begin{aligned}
& 0=X A_{p}^{\mathbf{T}}+A_{p} X-X M_{p}^{\mathbf{T}} V^{-1} M_{p} X+W \\
& 0=K A_{p}+A_{p}^{\mathbf{T}} K-K B_{p} \mathbf{R}^{-1} B_{p}^{\mathbf{T}} K+C_{p}^{\mathbf{T}} Q C_{p} .
\end{aligned}
$$

\section{Effect of Parameters on Helicopter FCS's Control Effort}

In this study, the effect of simultaneous variation in blade root chord length and blade taper on the control effort of the FCS of a helicopter is investigated. For this purpose, complex, control-oriented, physics-based helicopter models (see [12] for more details) which are trimmed and linearized around hover, 40-knot straight-and-level flight condition, and 80-knot straight-and-level flight condition are benefited. OVCs are designed with output variance constraints on helicopter Euler angles (i.e., $10^{-4}$ ), while all four helicopter controls are used as inputs. The noise intensities are $W=$ $10^{-1} * I_{25}$ and $V=10^{-1} * I_{4}$.

Figure 6 shows the effect of simultaneous variation in blade root chord length and blade taper on the control effort of the FCS of a helicopter for hover, 40-knot straight-andlevel flight condition, and 80-knot straight-and-level flight condition, respectively. As shown in the figure, when a positive taper (i.e., $\left.\Omega=1-\left(c_{T} / c_{R}\right)\right)$ is used, the control effort of the FCS of the helicopter increases for all three flight conditions. On the other hand, increasing the blade root chord length, which is obtained using the formula $c_{R}=c_{R_{0}} * \xi$, decreases the control effort. Therefore, it should be followed by the designers that if the blade taper is used due to the rotor performance reason or any other reason then the blade root chord length is required to be increased in order not to increase the control effort or energy consumption. Our extensive analyses show that this result is valid for different flight conditions (e.g., for hover and 80-knot straight-andlevel flight condition).

\section{Effect of Parameters on Closed-Loop Responses}

In order to better estimate the influence of simultaneous variation in blade root chord length and blade taper on the control effort of the FCS of a helicopter, the closed-loop performances of a classical helicopter, a helicopter with a 1st version blade taper and root chord variation, and a helicopter with a 2 nd version blade taper and root chord variation are compared. For the subsequent discussions, the closed-loop system obtained via integration of the classical helicopter and the OVC designed for it is referred to as the 1st closed-loop system. Similarly, the closed-loop system obtained via integration of the helicopter with the 1st version blade taper and root chord variation and the OVC designed for it is referred to as the 2 nd closed-loop system. The closed-loop system obtained via integration of the helicopter with the 2 nd version blade taper and root chord variation and the OVC designed for it is referred to as the 3rd closed-loop system. When the 1st version blade taper and 
Effect of blade taper and root chord on control energy for hover

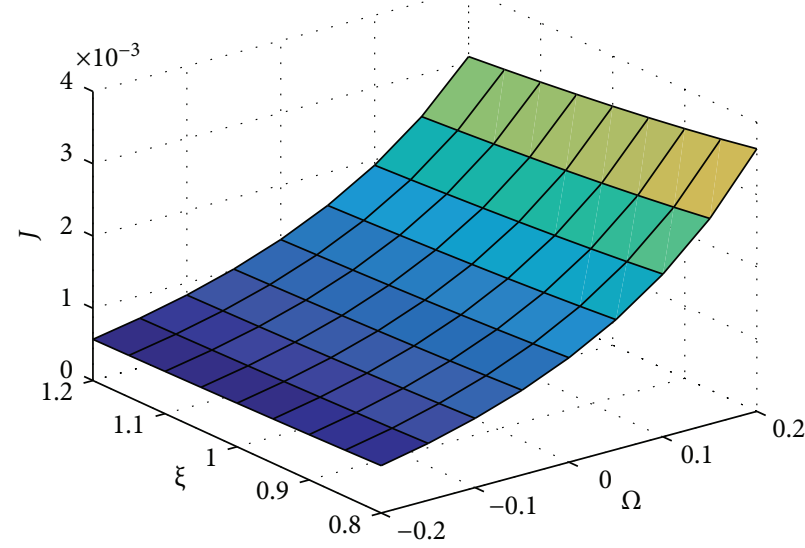

(a) Original plot for hover

Effect of blade taper and root chord on control energy for 40 knot

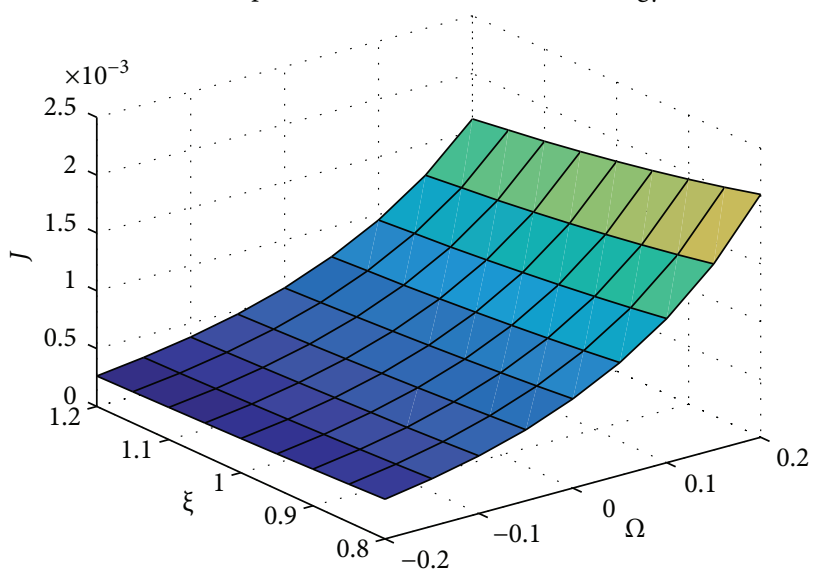

(c) Original plot for 40-knot SLFC

Effect of blade taper and root chord on control energy for 80 knot



(e) Original plot for 80-knot SLFC
Effect of blade taper and root chord on control energy for hover

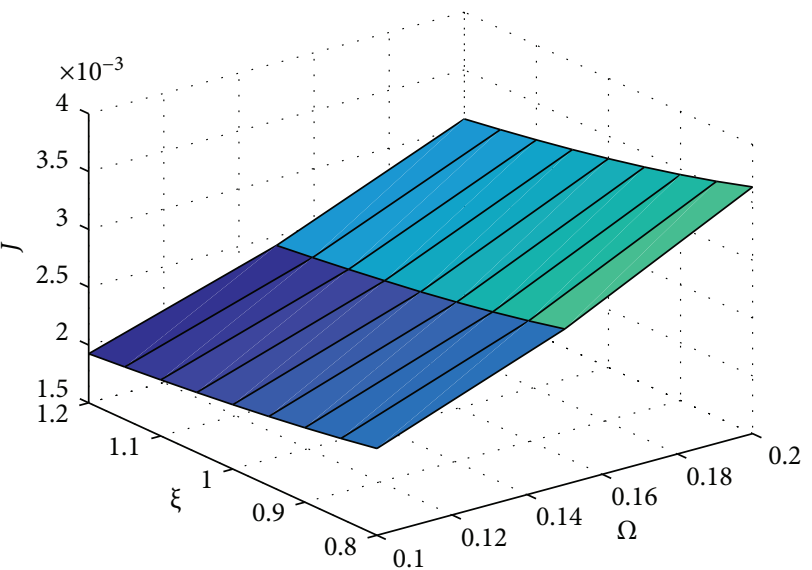

(b) Zoomed plot for hover

Effect of blade taper and root chord on control energy for 40 knot

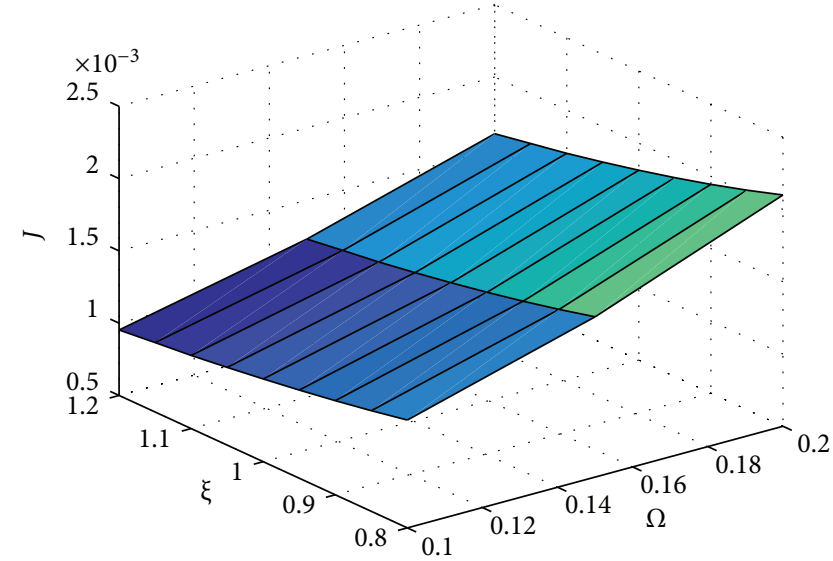

(d) Zoomed plot for 40-knot SLFC

Effect of blade taper and root chord on control energy for 80 knot

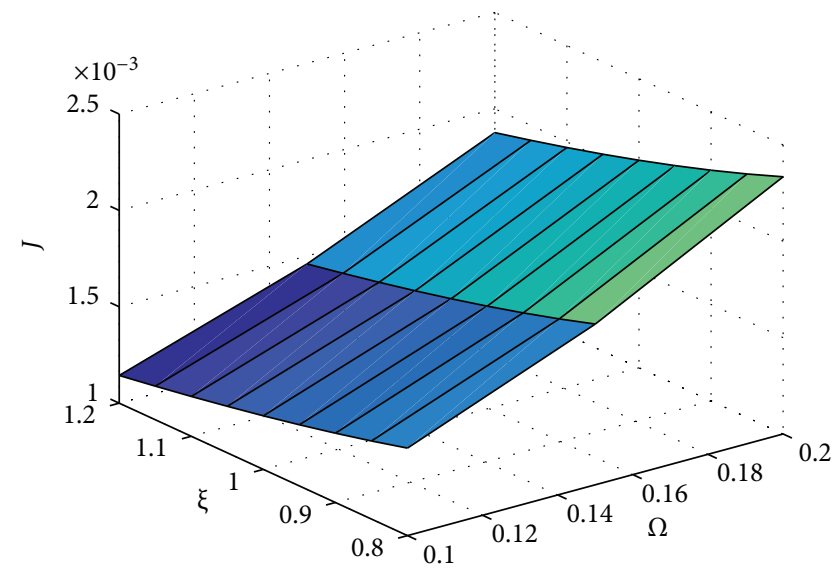

(f) Zoomed plot for 80-knot SLFC (SLFC: straight-and-level flight condition)

FIGURE 6: Effect of simultaneous variation in blade root chord and blade taper on the control effort (i.e., control energy) of the FCS of a helicopter.

root chord variation are applied, the root chord constant must be equal to $\xi=2 /(2-\Omega)$ to keep the blade area constant. Because $\Omega=0.2$ in this application, the value of $\xi$ is
1.1111. Moreover, when the 2nd version blade taper and root chord variation are applied, in order to decrease the control effort of the FCS of the helicopter when $\Omega=0.2$, the variation 

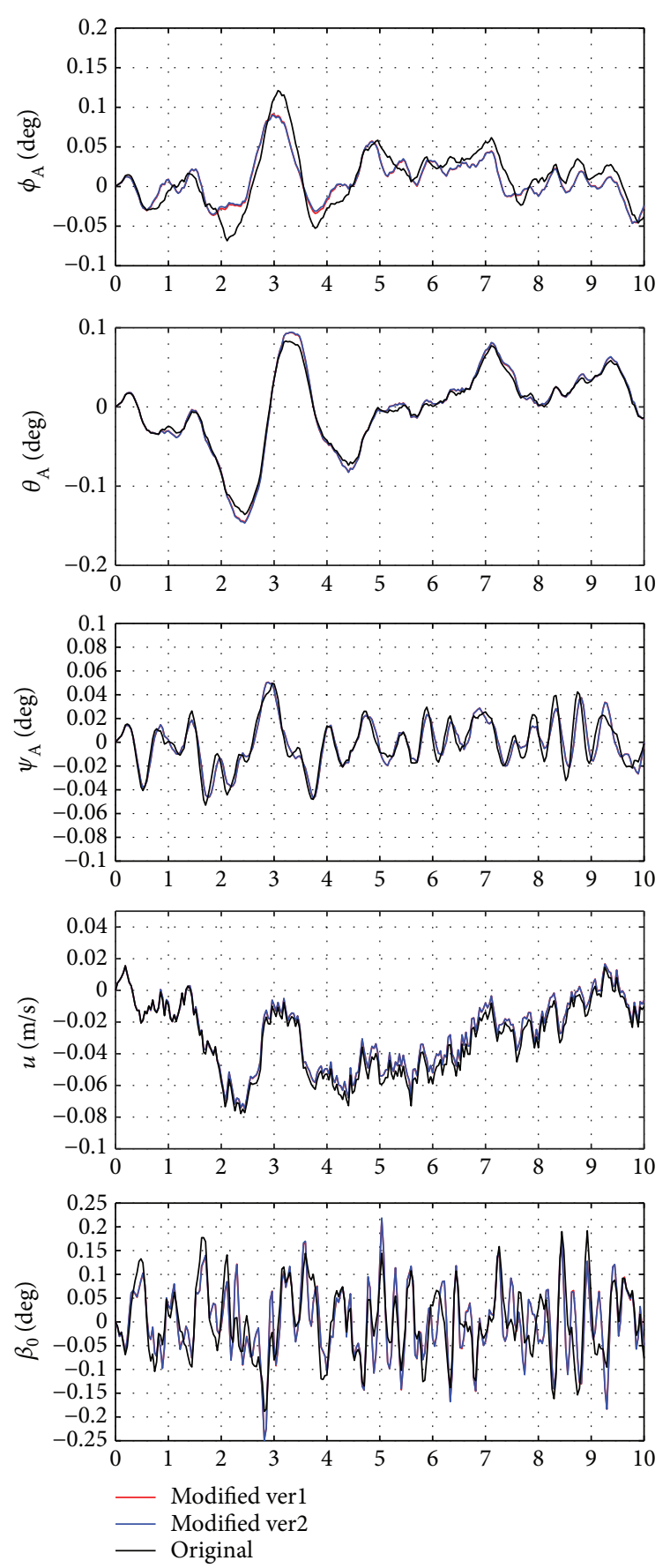

FIGURE 7: Effect of simultaneous variations in blade root chord and blade taper on some states for 40-knot SLFC.

in the blade root chord is increased to $\xi=1.2(\Omega=0.2$ and $\xi=1.2$ are border values for our study). For all these three closed-loop systems, helicopter models are trimmed and linearized for the 40-knot straight-and-level flight condition. In the figures shown below, the variables are represented in degrees to show their behaviors in a better way. It is also important to note that as linearized models are used, the actual values of the variables deviate from their trim values in the figures shown below. Moreover, these figures also show the closed-loop responses of some states and controls when
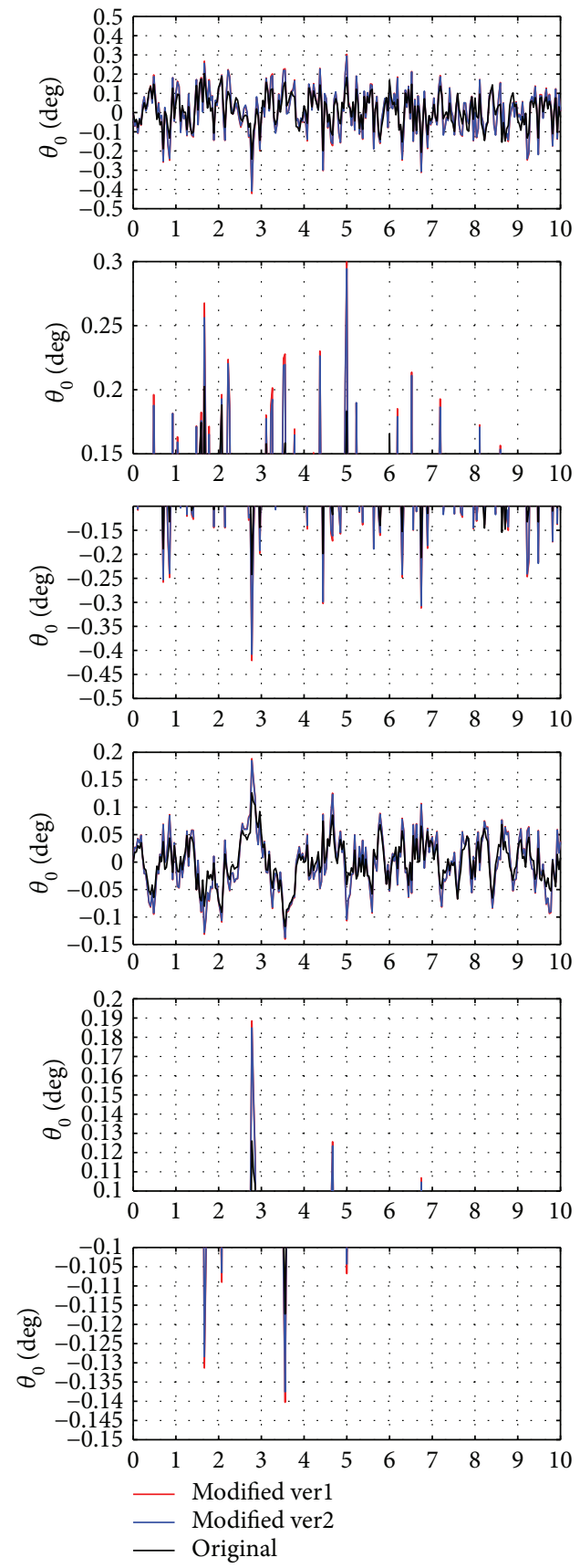

FIgURE 8: Effect of simultaneous variations in blade root chord and blade taper on some controls for 40-knot SLFC.

the closed-loop systems (solid black line) are all excited by white noise perturbations.

As shown in Figure 7, the qualitative (i.e., the shape of the response) and quantitative (i.e., the magnitude of the response) behaviors of the Euler angles are fundamentally the same for all the three helicopters. This can be explained by the fact that the expected values $\left(E_{\infty} y_{i}^{2}\right)$ of the outputs of interest (i.e., the helicopter Euler angles in this research article) are very close and satisfy the constraints $\left(E_{\infty} y_{i}^{2} \leq \sigma_{i}^{2}\right)$.

Figure 7 shows the closed-loop responses of the linear velocities of the helicopter (i.e., $\phi_{\mathrm{A}}$ : roll angle; $\theta_{\mathrm{A}}$ : pitch 
angle; and $\psi_{\mathrm{A}}$ : yaw angle) states, longitudinal linear velocity (i.e., $u$ ) state, and collective blade flapping angle (i.e., $\beta_{0}$ ) state for the 1st closed-loop system (solid black line), 2nd closedloop system (solid red line), and 3rd closed-loop system (solid blue line).

As shown in the figure, the other outputs (e.g., $u$ and $\beta_{0}$ ) do not show a catastrophic behavior, which implies that fast and large variations do not occur. The qualitative behaviors are similar for the three helicopters. This good performance can be explained by the exponentially stabilizing effect of OVC (see [12] for more details). Finally, for the different flight conditions (e.g., hover and 80-knot straight-and-level flight condition), the results found are also valid.

Figure 8 shows the closed-loop responses of some helicopter controls (i.e., main rotor collective and longitudinal cyclic blade pitch angles) for all the three helicopters. The most important observation related to variations in the taper and root chord of the main rotor collective blade pitch and longitudinal cyclic controls for all the three helicopters is that the peak values are the smallest for the 1st closed-loop system (i.e., integration of classical helicopter and OVC). Moreover, the peak values of the 2nd closed-loop system are greater than those of the 3 rd closed-loop system. These results can be explained by the fact that the control effort of OVCs (see (3)) existing in the related closed-loop systems is $8.18 * 10^{-4}, 16.89 * 10^{-4}$, and $16.08 * 10^{-4}$, respectively. Moreover, the control variations are smooth and small. Furthermore, controls do not show catastrophic behavior. Our extensive analyses also demonstrate that these results are valid for all the other controls (i.e., main rotor lateral cyclic blade pitch control and tail rotor control). Finally, the previously obtained results are also valid for the different flight conditions (e.g., hover and 80-knot straight-andlevel flight condition).

\section{Conclusions}

This study investigated the effect of blade root chord length and blade taper (i.e., in both the chordwise and lengthwise directions simultaneously) on the control effort of the FCS of a helicopter, as well as on the closed-loop responses, is investigated. For this purpose, helicopter models (complex, control-oriented, and physics-based models) including helicopter main physics and essential dynamics were used. Three closed-loop systems (i.e., for a classical helicopter, for a helicopter with blade taper and root chord variation, applied in order to keep the blade area fixed, and for a helicopter with taper and root chord variation at the borders) were examined.

When it is necessary to use taper owing to performance reasons, the length of the blade root chord must also be increased in order to not increase the control effort of the FCS of the helicopter. This result is also valid for different flight conditions (e.g., hover and 80-knot straight-and-level flight condition). For example, for our unmodified helicopter (i.e., Puma SA 330), the control effort was obtained as 8.18 $* 10^{-4}$ during 40 -knot straight-and-level flight condition. When the taper was chosen at the border and the root chord constant was chosen in order to keep blade area constant, the control effort was obtained as $16.89 * 10^{-4}$. Moreover, when both taper and the root chord constant were chosen at the borders, the control effort was obtained as $16.08 * 10^{-4}$.

Several important results regarding closed-loop systems were also obtained. First, as variance constraints on the outputs of interest (i.e., helicopter Euler angles) are identical for all closed-loop systems (one obtained for the classical helicopter and two others obtained for different taper and root chord variations), the qualitative (i.e., the shape of the response) and quantitative (i.e., the magnitude of the response) behaviors are principally the same. Moreover, the other outputs (e.g., linear velocity states, blade flapping states) do not show any catastrophic behavior. Second, the peak values of the controls (e.g., main rotor collective and longitudinal cyclic blade pitch angles) are the smallest for the 1st closed-loop system. Furthermore, the peak values of the 2nd closed-loop system are greater than those of the 3 rd closed-loop system. The previous two results were obtained because the control effort value is the smallest for the classical helicopter and the largest for the 2nd closedloop system. Finally, all the results obtained for the closedloop systems are also valid for different flight conditions (e.g., hover and 80-knot straight-and-level flight condition).

\section{Conflicts of Interest}

The authors declare that they have no conflict of interests regarding the publication of this paper.

\section{Acknowledgments}

This work was supported by Research Fund of the Erciyes University, Project no. FBA-2015-5954.

\section{References}

[1] T. Oktay and F. Sal, "Helicopter control energy reduction using moving horizontal tail," The Scientific World Journal, vol. 2015, Article ID 523914, 10 pages, 2015.

[2] J. E. Bluman and F. S. Gandhi, "Reducing trailing edge flap deflection requirements in primary control with a movable horizontal tail," Journal of the American Helicopter Society, vol. 56, no. 3, pp. 1-12, 2011.

[3] T. Oktay and C. Sultan, "Simultaneous helicopter and controlsystem design," Journal of Aircraft, vol. 50, no. 3, pp. 911-925, 2013.

[4] T. Oktay and C. Sultan, "Flight control energy saving via helicopter rotor active morphing," Journal of Aircraft, vol. 51, no. 6, pp. 1784-1804, 2014.

[5] Ö. Özdemir and M. O. Kaya, "Flapwise bending vibration analysis of a rotating tapered cantilever Bernoulli-Euler beam by differential transform method," Journal of Sound and Vibration, vol. 289, no. 1-2, pp. 413-420, 2006.

[6] O. O. Ozdemir and M. O. Kaya, "Energy expressions and free vibration analysis of a rotating double tapered Timoshenko beam featuring bending-torsion coupling," International Journal of Engineering Science, vol. 45, no. 2-8, pp. 562-586, 2007.

[7] N. A. Vu, J. W. Lee, and J. I. Shu, "Aerodynamic design optimization of helicopter rotor blades including airfoil shape for 
hover performance," Chinese Journal of Aeronautics, vol. 26, no. 1, pp. 1-8, 2013.

[8] D. Hodges, J. Ho, and W. Yu, "The effect of taper on section constants for in-plane deformation of an isotropic strip," Journal of Mechanics of Materials and Structures, vol. 3, no. 3, pp. 425-440, 2008.

[9] S. Kambampati and R. Ganguli, "Nonrotating beams isospectral to tapered rotating beams," AIAA Journal, vol. 54, no. 2, pp. 750-757, 2016.

[10] T. Oktay and F. Sal, "Blade taper effect on control effort and Puma SA 330 application on simulation environment," in 2nd International Symposium on Sustainable Aviation (ISSA 2016), Istanbul, Turkey, 2016.

[11] T. Oktay and F. Sal, "Effect of combined blade root chord length and blade taper on manned helicopter control effort," in 6th International Research Conference on Science, Management and Engineering (IRCSME 2017), pp. 1-3, Dubai, UAE, January 2017.

[12] T. Oktay, Constrained Control of Complex Helicopter Models [Ph.D. Thesis], Virginia Tech, Blacksburg, VA, USA, 2012.

[13] R. E. Skelton and C. Sultan, "Controllable tensegrity: a new class of smart structures," in Proceedings SPIE 3039, Smart Structures and Materials 1997: Mathematics and Control in Smart Structures, San Diego, CA, USA, 1997.

[14] R. E. Skelton and M. Delorenzo, "Space structure control design by variance assignment," Journal of Guidance, Control, and Dynamics, vol. 8, no. 4, pp. 454-462, 1985.

[15] R. W. Prouty, Helicopter Performance, Stability and Control, Krieger Publishing Company, Melbourne, FL, USA, 2002.

[16] R. W. Prouty, Military Helicopter Design Technology, Krieger Publishing Company, UK, 1998.

[17] G. J. Leishman, Principles of Helicopter Aerodynamics, Cambridge University Press, UK, 2006.

[18] A. V. Reddy, M. V. Kumar, and G. Gurrala, "Novel approach for the design of state feedback power system stabilizers," in 2010 International Conference on Power System Technology, pp. 1-5, Hangzhou, China, 2010. 


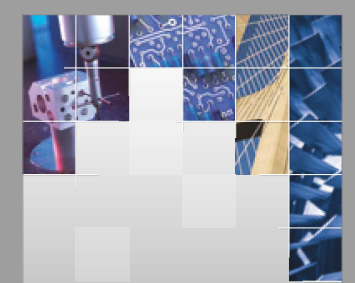

\section{Enfincering}
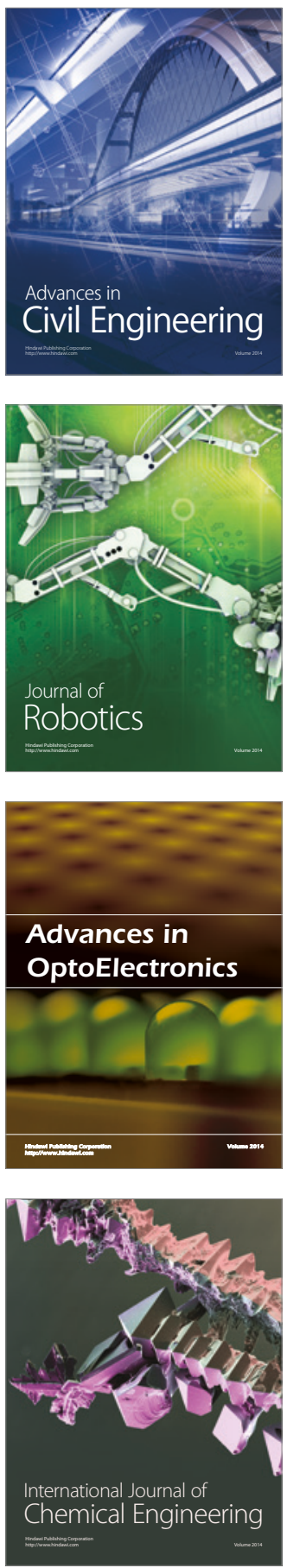

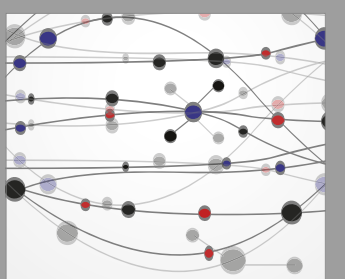

The Scientific World Journal

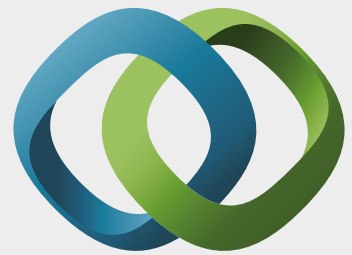

\section{Hindawi}

Submit your manuscripts at

https://www.hindawi.com
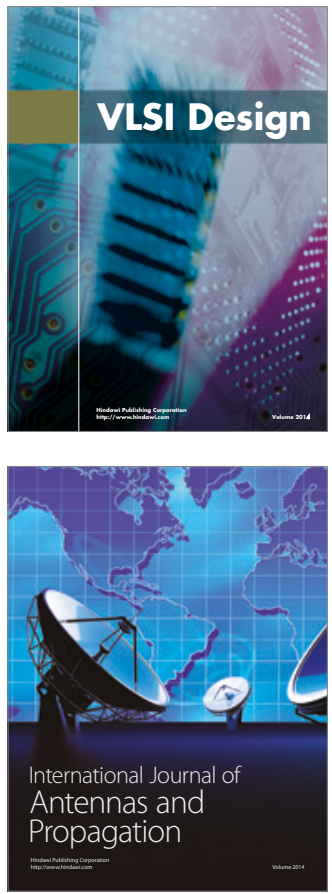

\section{Rotating}

Machinery

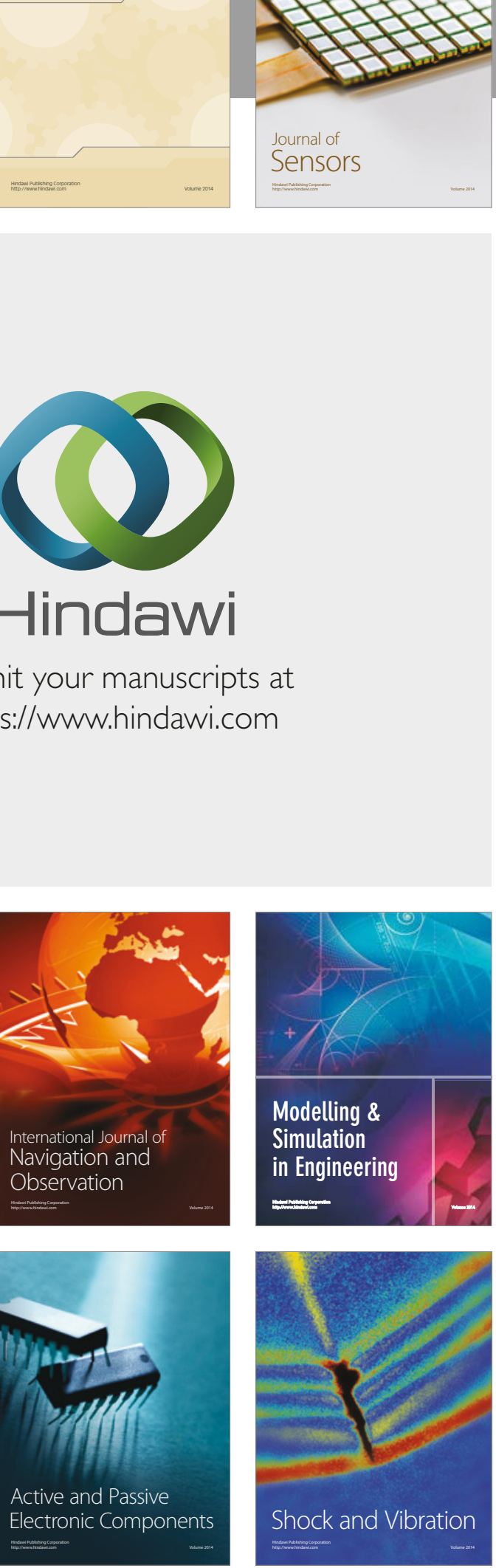
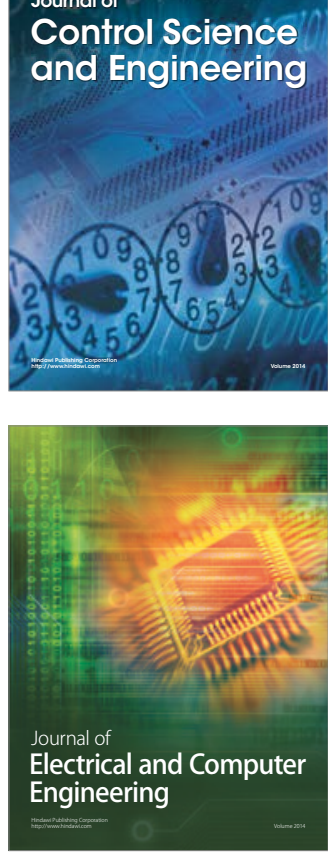

Distributed

Journal of

Control Science

and Engineering
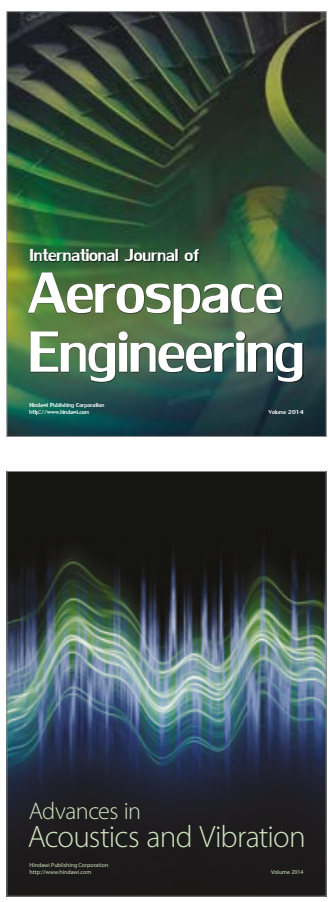

Sensor Networks 